\title{
Financial and Legal Background of State and Banking Incentives for Digital Transformation of the Cultural Sphere During the COVID-19 Pandemic
}

\author{
E.V. Pokachalova ${ }^{1, *}, A . S$. Alimbekova $^{1}, T . A$. Malysheva $^{2}$, and E.A. Eremina $^{3}$ \\ ${ }^{1}$ Saratov State Law Academy, Saratov, Russia \\ ${ }^{2}$ Saratov State University, Saratov, Russia \\ ${ }^{3}$ Yuri Gagarin State Technical University of Saratov, Saratov, Russia
}

\begin{abstract}
The article is devoted to measures of state and banking stimulation of the digital transformation of cultural organizations during the COVID-19 pandemic, as well as the need for legal understanding of such concepts of Russian legislation as financial support, methods of financial support. The authors of the study propose regulatory changes to improve the financial and legal mechanism of interaction between participants in tax and public banking legal relations, including government bodies, as well as representatives of the banking sector to provide financial support to cultural organizations. It has been concluded that the state is the main subject of financial support for cultural organizations in Russia during the spread of the COVID-19 pandemic. At the same time, at the institutional level, the financial and legal regulation of the provision of such financial assistance has yet to be built.
\end{abstract}

\section{Introduction}

Following the closure of borders between the states, measures of social distancing, some of the most significant and meaningful transformations have taken place in the management system of the cultural sphere. On the one hand, tours have been canceled in all countries of the world, theaters, museums, and cultural centers have been closed. On the other hand, many of the spheres of cultural activity turned out to be the readiest for the transition to a digital way of work, as a result of which the sphere of culture became the most important source of maintaining the emotional state of people.

At the same time, according to the estimates of the United Nations Educational, Scientific and Cultural Organization (hereinafter - UNESCO), the cultural sphere includes almost 30 million jobs around the world, due to which cultural workers turned out to be one of the most economically affected categories of the population [1 ].

At the beginning of March 2020, most cultural institutions around the world were closed for an indefinite period, the programs of their events were canceled or postponed.

\footnotetext{
${ }^{*}$ Corresponding author: pokinarod@mail.ru
} 
Despite the fact that theaters and museums switched to online broadcasts, mastered new formats of performances, significant financial losses are observed in the cultural sphere [2, 3]. Small municipal institutions, heavily dependent on ticket sales, faced the threat of a complete loss of income from income-generating activities during the restriction period. At the same time, UNESCO informs that "even if museum complexes are opened within the next 18 months, a significant decrease in the flow of visitors is expected due to a decrease in international tourism. In this regard, many museums find themselves on the verge of bankruptcy and are forced to adapt to new circumstances" [4].

The transition to the online environment will not be able to become a tool available to all cultural organizations, due to the limitations of their resources or the capabilities of the digital infrastructure, which makes the presented study relevant, the main goal of which is to develop the recommendations for improving the financial and legal support of the digital transformation of the cultural sphere through tax and banking legal regulation, benefits and incentives.

\section{Materials and methods}

In the presented study, theoretical methods of formal and dialectical logic, special comparative legal and formal legal methods have been used. When studying the Russian financial legislation, which establishes the legal basis for the digital transformation of the cultural sphere, formal legal, methods of analysis and synthesis have been used. Using the comparative legal method, it was possible to identify the positive aspects of the experience of financial (including budgetary, tax and banking) support of cultural organizations by foreign countries.

\section{Results and discussions}

Digital transformation of the cultural sphere took place in the shortest possible time, which was significantly influenced by the trajectory of the previous development in this direction. However, if such technologies have previously existed, but were have been the product of the largest and most successful cultural institutions, then in the context of restrictive measures, the online format had to be mastered by all cultural institutions without exception.

Digitalization, like any process of transition to a new innovative level of development of public relations in various spheres of the economy, requires some regulatory control [1]. In addition, such a complex of measures requires significant financial investments in the technical sphere and a completely different approach to human resources.

M.Kh. Duguzhev and E.P. Simaeva argue that "The transition to digital platforms and the use of high-tech solutions in the cultural sphere require possession of digital skills, in other words, possession of digital competence" [5].

The growing interest in digital products in the field of culture brings a number of other challenges to be addressed. The main thing is the lack of financial resources of cultural institutions - the financial basis of their activities is budget financing within the framework of the system for ensuring the fulfillment of the state task.

In response to the crisis caused by the pandemic, states and international organizations are taking both financial and organizational measures to support the industry. In many countries, governments and authorities with the competence to formulate and implement cultural policies have implemented packages of measures to support the industry [2]. Including financially supported independent cultural workers who do not have access to financial resources of institutions. Thus, in Ireland, Luxembourg, Poland, France and 
Switzerland, social benefits are provided to independent artists [6]. In Spain and the Republic of Korea, cultural workers are provided with concessional loans [6]. In Australia, institutions were granted a deferral for loan repayments, allowed to redistribute previously targeted funds between different budget lines. In the Republic of Korea, tax liabilities for cinemas have been reduced. [6]

Private companies, including the banking sector, did not stand aside either. In the United States, funds have been formed at various levels of government to support the arts, crafts, music, and literature. Netflix has committed \$ 100 million to support the audiovisual workers. The African Development Bank (AfDB) has committed \$ 10 billion to implement a pandemic response package. [6]

In Russia, the legal basis for the first measure to support cultural institutions was the order of the Government of the Russian Federation dated May 08, 2020 No. 1231-p, according to which the Ministry of Culture of Russia, federal state budgetary institutions of culture allocated funds up to $3,808,500$ thousand rubles in 2020 from the reserve fund of the Government of the Russian Federation to provide the subsidies in order to provide state support to cultural institutions whose activities were completely or partially suspended due to the spread of coronavirus infection. At the same time, the Ministry of Culture of Russia was obliged to provide the subsidies based on the results of monitoring the financial condition and assessing the needs of institutions to finance the priority costs.

In addition, the provision of financial state support was assumed within the framework of measures to support systemically important organizations", which provides the basis for the selection of organizations included in the industry lists of systemically important organizations, applying for state support, including: the provision of subsidies, in accordance with Part 1 of Article 78 of the RF BC, deferral (payment by installments) for the payment of taxes, advance payments for taxes; state guarantees of the Russian Federation for loans or bonded loans.

Later, the issues of the activities of cultural institutions were included in the national plan for economic recovery, where attention was paid to the restoration of the activities of libraries, without adjusting the state orders.

The advanced position of the libraries during the quarantine measures was largely ensured by the equipment of model libraries within the framework of the national project "Culture", which are provided with high-speed Internet, access to electronic resources, and digitized documents.

In May 2018, the President of the Russian Federation V.V. Putin issued the Decree of the President of the Russian Federation dated May 7, 2018 No. 20 (as amended on July 21, 2020) "On national goals and strategic objectives of the development of the Russian Federation for the period up to 2024", according to which 12 priority directions of the country's development have been identified, according to which the Government of the Russian Federation was obliged to form the appropriate National Projects (hereinafter National Projects) and programs, among which the sphere of culture has been also indicated. In 2020, the negative impact of the new coronavirus pandemic in the world triggered the postponement of the implementation of national projects to 2030. The structure of the national project includes three federal projects, one of which "Digital Culture" is aimed at "digitalization of services and the formation of an information space in the field of culture." It follows that digitalization of the sphere had been one of the significant areas of activity of the Ministry of Culture of Russia even before the start of the COVID-19 pandemic.

Despite the fact that the national goals are being implemented for the second year already, questions still remain. So, Yu.A. Tikhomirov and E.V. Talapina note the imperfection of the legal regulation of project activities, pointing to the inconsistency of many program documents, the intersection of their goals and objectives [7]. 
According to the above-mentioned Decree, the sphere of culture is not included in the transformation plan through the national program "Digital Economy of the Russian Federation". In this regard, it seems necessary to provide for the features of the digitalization of culture in this program, and to ensure the formation of its regulatory and legal framework.

It is now becoming clear that it is not possible to reliably predict the timing of the end of the COVID-19 coronavirus pandemic. In this regard, it seems necessary to dwell on the question: what, in general, from a legal point of view, is support for organizations of cultural activities?

At the moment, neither the Fundamentals of Legislation on Culture, nor the strategic planning documents in the field of culture stipulate the institution of "support" for cultural institutions. The legislation regulating the financing of the sphere of science is of special interest, which is no less important for the development of the country and the maintenance of human capital in Russia.

Chapter IV.1 of the Law "On Science and State Scientific and Technical Policy" defines in detail the principles, subjects and forms of providing the state support for the innovations. Of course, the legal regulation of two different spheres of public life, both in administrative processes and in terms of funding model, should not duplicate each other. However, it is the inclusion of the institution of legislative support in the backbone normative legal act that is the most important guarantee of the development of the sphere.

E.V. Talapina, considering the legal novelties of digital transformation in France, notes multi-level regulation (state, independent authorities, private), cooperation between government and business; active public participation, and significant government support (subsidies for Internet connectivity, digital skills training, support for vulnerable citizens) as characteristic features of digitalization in France [8]. It is no secret that cultural institutions as a whole exist in many Anglo-Saxon countries at private expenses with a small share of state financial support [9].

For this reason, it seems necessary to introduce into section VIII "Economic regulation in the field of culture" of the Fundamentals of Legislation on Culture, the appropriate regulatory and legal changes aimed at regulating public relations between subjects of cultural activity, government and local authorities, as well as representatives of the private sector in the provision of public and private support for cultural activities.

Among the representatives of the private sector, banks stand out favorably, which can become subjects of financial support to cultural organizations, since they have impressive financial resources. It should be noted here that federal cultural institutions are in a longterm partnership with major Russian banks, such as the Pushkin Museum and the VTB Bank, or the State Hermitage and Sberbank. At the same time, it is much more difficult for institutions of the constituent entities of the Russian Federation, and even more so for municipal cultural institutions to enlist the support of such serious sponsors.

It seems that during a pandemic, the state could support cultural organizations by indirect methods, for example, by tax incentives for patronage institutions and charitable activities by providing sponsors, incl. banks, the right to tax deductions for income tax. In particular, we can talk about granting the right to include in the investment tax deduction for corporate income tax (Article 286.1 of the Tax Code of the Russian Federation) expenses in the form of donations to organizations operating in the field of culture at the federal level.

\section{Conclusion}

The cultural sector, amid the COVID-19 coronavirus pandemic, has become one of the prime examples of rapid digital transformation. And first of all, this became possible thanks 
to the prompt response of cultural institutions to crisis phenomena. At the same time, like any new social relations, for their own development, they must be inscribed in the legal field.

During the pandemic, the Russian Federation became the main subject of financial support for cultural organizations. However, due to the eccentricity of the context in which both the organizations themselves and the state authorities were placed, the existing order of targeted support of cultural institutions needs a certain streamlining.

In connection with the foregoing, it seems appropriate to amend Russian legislation aimed at regulating public relations between subjects of cultural activity, state authorities and local governments, as well as representatives of the private sector, including the banking sector, to provide state support for cultural activities.

The designated areas of reforming the financial legislation could, to a certain extent, become the very guarantees necessary for cultural figures and ensure the improvement of the digital transformation of the cultural sphere.

\section{Acknowledgements}

The reported study was funded by RFBR according to the research project No 18-29-16102 "Transformation of legal personality of participants of tax, budgetary and public banking legal relationships in the context of development of digital economy".

\section{References}

1. Cultural times, The first global map of cultural and creative industries, 5 (2015) https://en.unesco.org/

2. Digest of the Audit Chamber of the Russian Federation, Culture, in the context of a pandemic COVID-19, 27 (2-2020), https://ach.gov.ru/

3. Reverse inclusion during lockdown. The experience of the Pushkin State Museum of Fine Arts, https://icom.museum/

4. Culture \& COVID-19. Impact and response tracker, 4, 6 (2020), https://en.unesco.org/

5. M.H. Duguzheva, E.P. Simaeva, Bulletin of Perm University, Forensic sciences, 44, 190 (2019)

6. Culture \& COVID-19, Impact and response tracker, 1, 4 (2020)

7. Yu.A. Tikhomirov, E.V. Talapina, Law, Journal of the Higher school of Economics, 1, 4 (2020)

8. E.V. Talapina, Law, Journal of the Higher school of Economics, 4, 164 (2019)

9. M.A. Zhokhova, Economic journal, 1, 158 (2013) 